\title{
A FEMALE SPIDER WITH ONE MALE PALPUS.
}

\author{
BY J. H. EMERTON, BOSTON, MASS.
}

THIs is a large specimen of Drassus saccatus Em. collected with other spiders

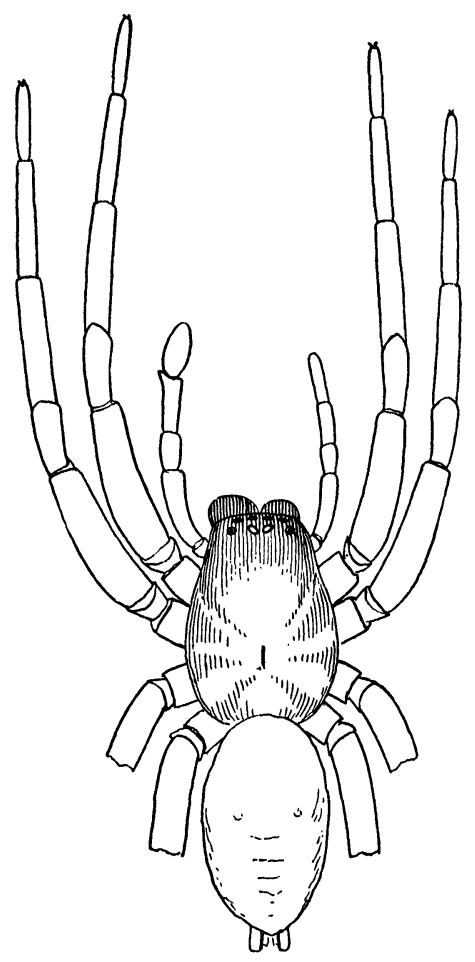
by Miss E. B. Bryant at Long Island, Portland, Me., Aug. 10, 1906, without its peculiarities being noticed at the time it was taken. The general appearance is that of an old female of large size with the abdomen small and shrivelled as in a female that has laid eggs. The epigynum is complete and symmetrical as in a normal female. The cephalothorax and abdomen are symmetrical and the third and fourth legs are alike on both sides. The right palpus is that of a female and the left that of a male with the palpal organ fully developed. The first and second legs of the left side are slightly longer than those of the right side. The left mandible is thicker than the right and the claw is slightly longer but the mandible is not elongated nor narrowed at the tip as it is in the male. Asymmetry of any kind is rare in spiders. Prof. W. M. Wheeler has called my attention to a case described by Kulczynski in one of the publications of the Cracow Academy of Sciences in 1885. This was an Erigone fusca Blk. which had the right side like the female and the left like the male. The epigynum was developed only on the right side and the asymmetry extended to the form of the cephalothorax and abdomen and even the spinnerets. The legs however were symmetrical in length, the only difference being in those of the first pair which had the right tarsus like the female and the left like the male. 

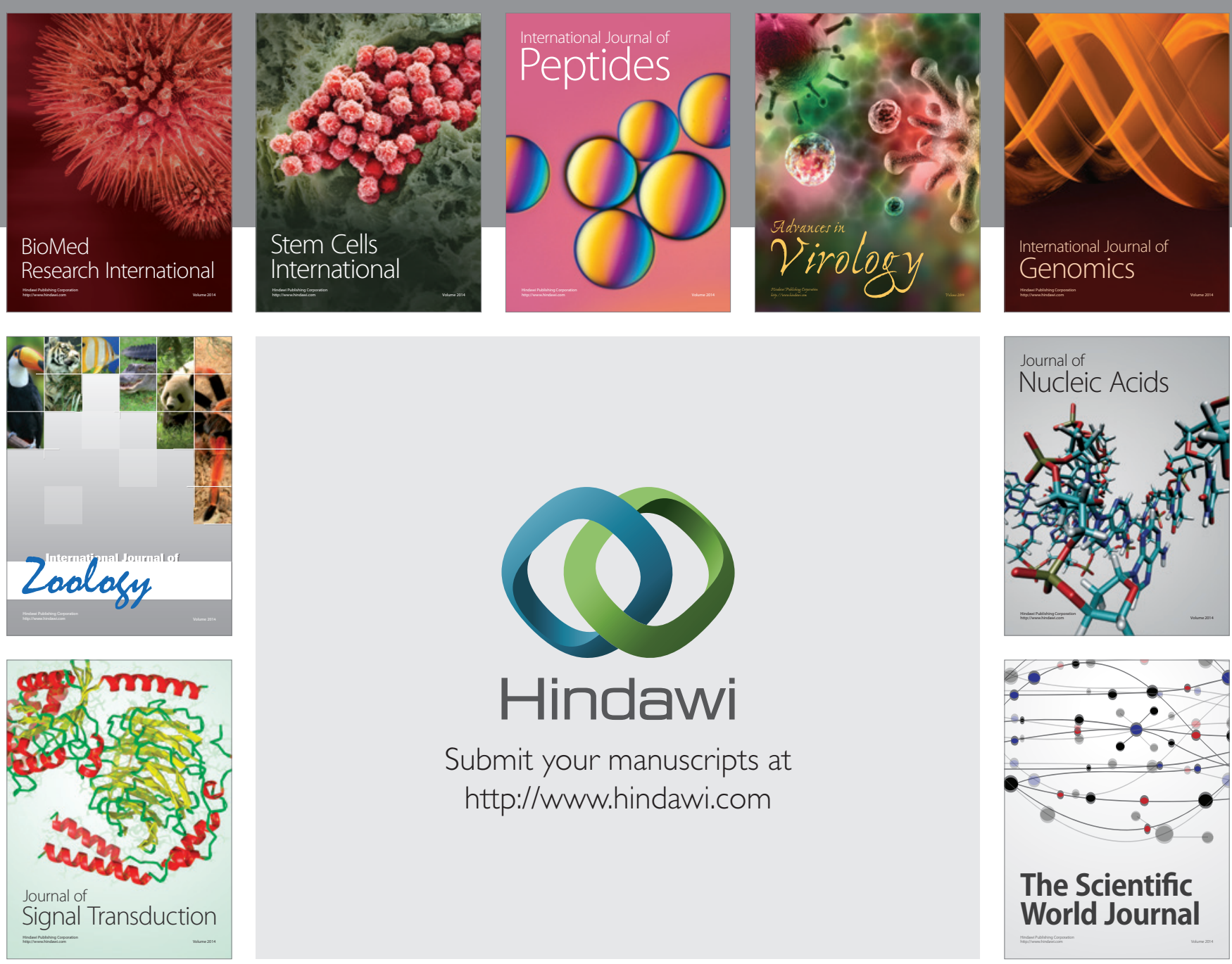

Submit your manuscripts at

http://www.hindawi.com
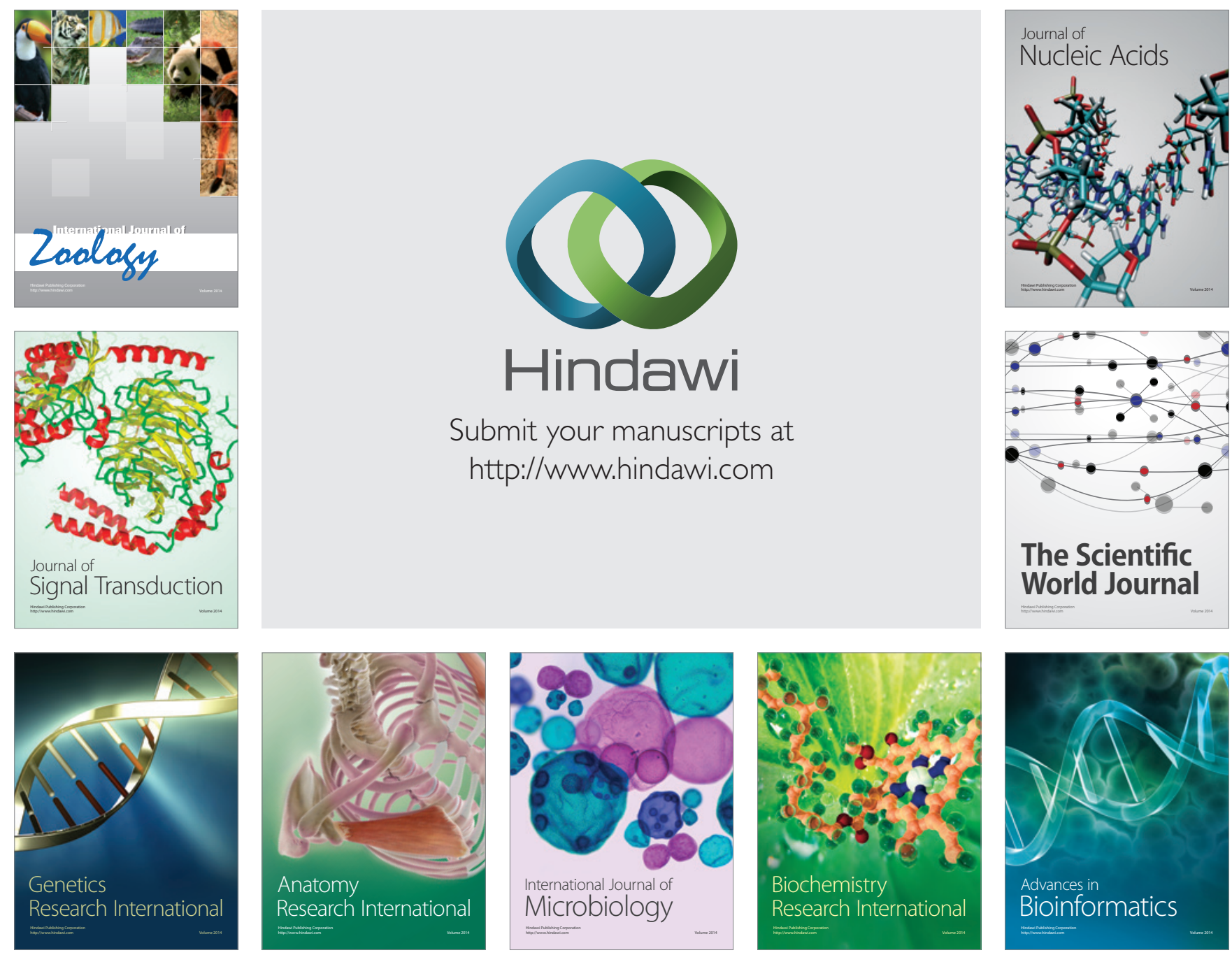

The Scientific World Journal
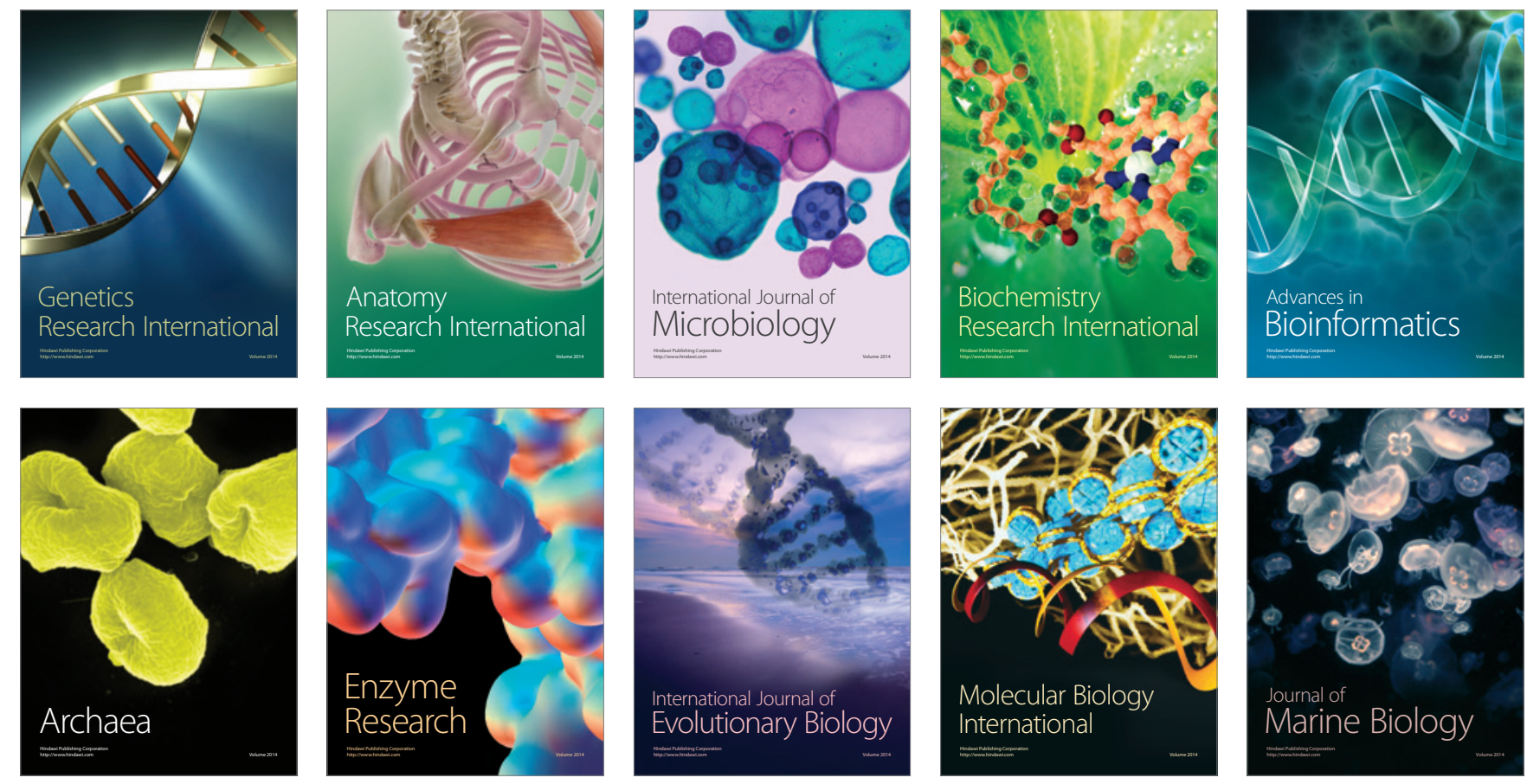